\title{
Manufacturing operations management systems in small and medium business (discrete manufacturing)
}

\author{
Michal Dic ${ }^{1}$, Miriam Pekarčíková ${ }^{1}$, Marek Kliment ${ }^{1}$, Ján Kopec ${ }^{1}$ \\ 1 Technical University of Košice, Faculty of Mechanical Engineering, Institute of \\ Management, Industrial and Digital engineering, \\ Park Komenského 9, 04200 Košice, Slovakia \\ michal.dic@gmail.com \\ miriam.pekarcikova@tuke.sk \\ marek.kliment@tuke.sk \\ jan.kopec@tuke.sk
}

\begin{abstract}
Annotation: This article deals with Manufacturing Operations Management / Manufacturing Execution Systems for Small and Medium Business as specific type of companies. Many times, those companies do not have resources to follow full complexity of Manufacturing Operations managements system and need to select only products which they are forced to have due to internal or external regulations. Rest of the product are many times either substitute with simple solution like spreadsheets or not present at all. Successful implementation of each of those products means significant improvement in quality, reduced costs or higher efficiency.
\end{abstract}

\section{Introduction}

The market is becoming intelligent with help of technologies like data mining, artificial intelligence, geographical positioning system, internet and so many more to come. Every company has a fight to retain its customers and expand itself globally. But how does it achieve all these. The solution are Manufacturing Operations Managements systems. But due to the characteristic of Small and Medium Business and their possibilities to invest not full scope solution will cover their needs.

Competition in the next millennium increased emphasis upon time as expressed by speed, quality, service and global focus. Agility is the watchword. Manufacturers are measured by their ability to react quickly to sudden, often unpredictable change in customer demand for their products and services. To compete successfully the manufacturing applications have to be time and activity based and above all should be focused on customer. Today companies must be able to deliver customer specific products with the lead-time of standard, off the-shelf products. Make-to-stock and make-toorder types of modes at times have to be selected by the company.

The Human Resource management, business intelligence, supply chain management, customer-relationship management all are there existing in manufacturing companies. Now the major problem is that the company is 
proficient in manufacturing and production but does not have the expertise and assurance that all the above information islands can be merged together to give the best inputs to the decision makers and make life hassle free. Further we focus on the solution to challenges in a timely and cost-effective way. The main functionalities of Manufacturing Operations Management/ Manufacturing Execution System are described on pic 1.

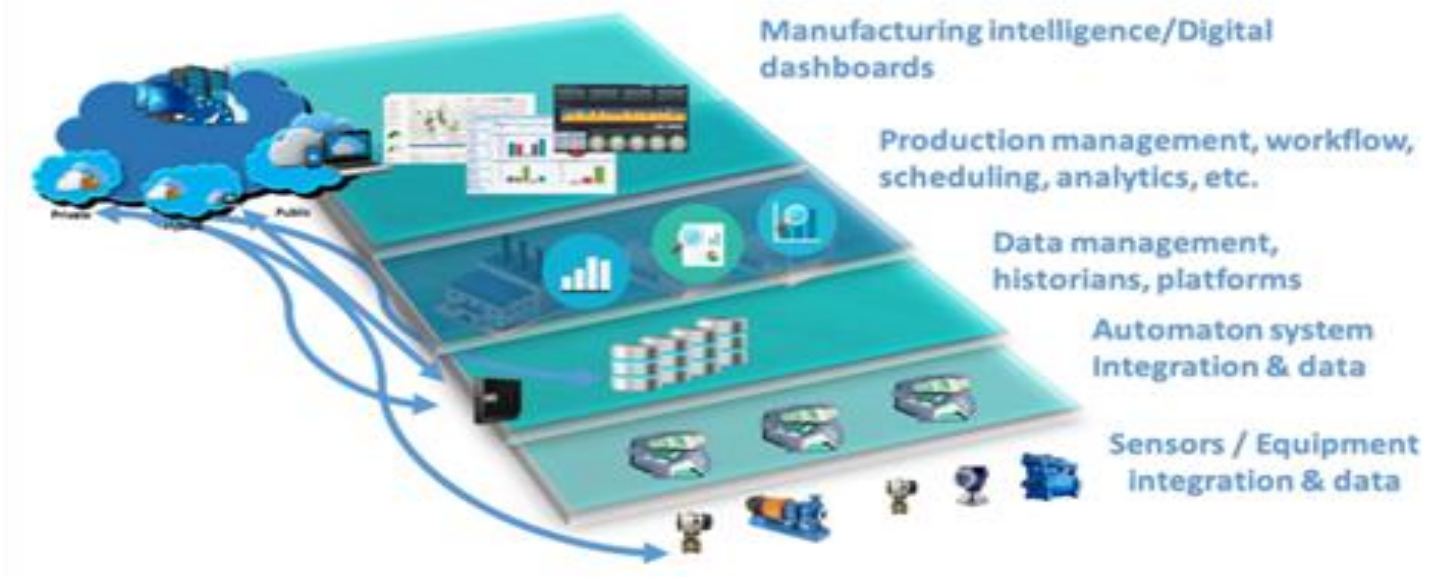

Pic 1 - Typical MES functionalities

Currently, the MES market consists of automation system suppliers, enterprise resource planning (ERP) and business system suppliers, product lifecycle management (PLM) suppliers, and independent suppliers. Most of these suppliers are adding MES functionality or integrating with the MES solution using new platform solutions causing an expansion and merging of capabilities. Some of the ERP and business systems suppliers do not have the same level of shop floor capabilities as the automation or traditional MES suppliers. But being able to integrate design and material information directly into the MES will have some advantages.

MES is the backbone for lower cost, higher quality, and faster production. It is the future for newer more complex and more personalized products. More MES functionality will be embedded in devices and equipment so that they govern themselves and take corrective action that helps them improve efficiencies and avoid unscheduled downtime. MES is the foundation for Industry 4.0 and smart manufacturing. Factories will enable real-time visibility globally across the entire value chain.

\section{Small and medium business (SMB)}

A small and midsize business (SMB) is a business that, due to its size, has different IT requirements and often faces different IT challenges than do large enterprises, and whose IT resources (usually budget and staff) are often highly constrained. Definition of SMB is different by the country and company but for research purposes for example Gartner defines SMBs by the number 
of employees and annual revenue they have. The attribute used most often is number of employees; small businesses are usually defined as organizations with fewer than 100 employees; midsize enterprises are those organizations with 100 to 999 employees.

The second most popular attribute used to define the SMB market is annual revenue: small business is usually defined as organizations with less than $\$ 50$ million in annual revenue; midsize enterprise is defined as organizations that make more than $\$ 50$ million, but less than $\$ 1$ billion in annual revenue.

\section{$3 \quad$ Manufacturing operations management / manufacturing execution system}

MES is designed to fulfil the needs of a broad manufacturing enterprise, by coupling front office accounting with the factory supervisory control systems and products. In addition to linking, MES also closely ties the outputs of these three layers of information systems those residing in the planning functions, such as MRP, execution functions, such as supervisory control software or quality control, and control systems that create the data utilized, so that the enterprise has full access to the separate databases of information that exist within the organization. MES's functions such as scheduling, resource allocation, process management, quality management, and operation analysis, all operate to "translate" the real-time data occurring on the factory floor into information that is useful from a process control/management standpoint. This further ripples into other adjunct processes such as labour, equipment, and materials management; product tracking; and supportive systems such as quality and documentation.

\subsection{Quality Management System}

Beyond visibility, the MES should provide tools to sustain quality improvements. This usually includes in-process inspection and verification steps, statistical process control (SPC), alerts, and defect and corrective action handling to help reduce or eliminate abnormal behaviour recurrence. In electronic, semiconductors, and machinery industries parts are rarely scrapped and usually re-worked, and reapproved by quality personnel, making it even more important to avoid deviations whenever possible.

\subsection{IT/OT Convergence}

Organizations are combining loT and IT technologies into OT systems and vice versa. The IT-OT convergence requires collaboration between IT and OT systems and organizations. MES is a key technology for IT-OT convergence because it helps close the gap between the different types of IT and OT technologies. While the functionality has not changed, there is some overlapping and merging of capabilities in the ERP and MES spaces. The traditional ISA levels are evolving into seamless functionality that will involve more services and analytics. Although there are still differences between IT 
and OT worlds, new platforms and standards are making it easier to converge and integrate data from different systems.

\subsection{Planning in SMB}

The central task of material requirements planning is to ensure material availability through supply management. This means procuring the necessary required quantities within the company and for sales at the proper time.

Clear picture what planning require might be described by the Pic $2-$ order lifecycle. Picture 2 deals with order coming from Customer directly to the customer and which processes needs to pass before it is produced.

This also includes monitoring stocks and creating procurement proposals for purchases. Here, demand planning strives to find the optimal path between

- Best possible supply readiness and

- Minimization of costs and capital lockup

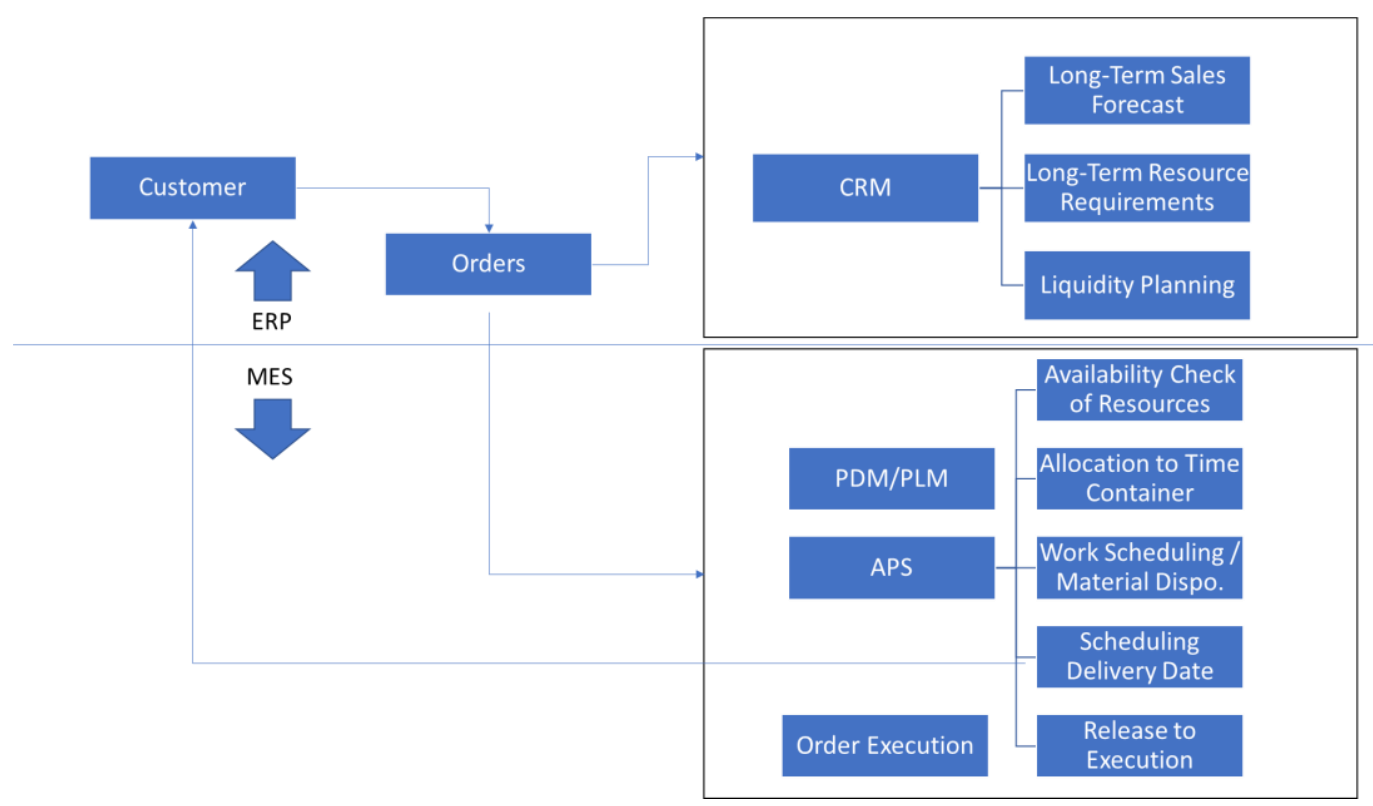

Pic. 2 - Lifecycle of the order

APS key elements

- Headcount - Reacting quickly to the absence of key workers

- Machine Breakdown - What can you do if you can't get parts or an engineer on-site to fix the machine?

- Stock Materials/Ingredients Shortage - What can you do if you cannot follow the day's original production schedule?

- Prioritising Orders - Which orders can be completed? How can you work most efficiently on the most valuable orders? 
- New and Temporary Staff - How can you maintain and increase efficiency with new and temporary staff?

- Order Enquiry- Can you deliver new orders on time? What would the impact be on existing orders?

\subsection{Implementation of APS in SMB}

Company first focused on the cold forming of tubes, but quickly specialized in the bending of all types of stainless steel and nickel alloys. Today the company has a dealer network in over +40 countries and sales approximately 30 mil $€$, over 60 percent in exports. Size of the company and product directly fits to SMB definition. Company selected Manufacturing Execution system (MES) and Advance planning and scheduling (APS) system to cover its needs. MES vertically integrates IT and OT networks and give right data to APS solution.

Due to the types of parts produced from custom-made and single piece to largescale production, the high number of referenced finished products $(7,000$ references, including 1,000 custom-made), the diverse materials used and various constraints, there was no choice but to set up a dedicated scheduling tool. Even though the company needed little persuasion, the following data convinced company it needed the capabilities of a real scheduling tool: The firm had 1,500 continuous work orders, 5,000 operations in the planning and 12 production areas, which included 260 work centres. Company IT architecture is like below: Infinite-capacity planning, bill-of-materials (BOM) and routes are managed in the enterprise resource planning (ERP) system. Work orders are passed on to APS, which is used to communicate with two other systems: The manufacturing execution system (MES) to update the planning according to the state of progress of the operations in the workshops, and the computerized maintenance management system (CMMS), which passes on the maintenance action requests.

Business Challenges which customer faced before implementing MOM / APS solution

- Implement a scheduling solution that can keep pace with the company's growth

- Manage diverse materials, part types and deadlines

- Increase manufacturing capacity

Results after implementing APS

- Increased administrative efficiency of work centres by 87 percent

- Improved the ability to meet deadlines and achieved a 96 percent ontime delivery rate

- Multiplied workload by $20 \mathrm{X}$ 
- Reduced the number of people administering work centres from three to one

\section{CONCLUSION}

As it was already pointed in the text above, companies belonging to small and medium business do not have capacity to acquire full MOM/ MES solution with all products in like quality management systems, business intelligence systems, LIMS or other. They need to pick the one which are "low hanging fruit" to cover most of the needs and the rest substitute with cheaper solutions. Many times, we might see this companies are focusing only on MES/APS as those solution brings highest value. Especially, Advance Planning and Scheduling Systems are the first option as they are solving the most common and the most costly parts of the manufacturing - efficient planning. Implementation of software which allows vertical integration between IT and OT many times is result of external pressure coming from legislative or customers so companies are not stepping further than APS solution if they don't need.

\section{Acknowledgements}

This article was created by implementation of the grant project VEGA 1/0438/20, KEGA 001TUKE-4/2020, APVV-17-0258 and APVV-19-0418.

\section{References}

[1] https://www.gartner.com/en/information-technology/glossary/smbs-smalland-midsize-businesses

[2] Web: http://ijniet.org/wp-content/uploads/2012/10/2PDF.pdf

[3] Framinan M. J., Leisten R., Garcia R.R.: Manufacturing Scheduling Systems - an Integrated View on Models, Methods and Tools, Springer, 2014, SBN 978-1-4471-6271-1

[4] SIEMENS - Key Facts and essentials for Impementing an APS System introduction to The Little Blue Book on Scheduling

[5] Mauergauz Y.: Advanced Planning and Schedulig in Manufacturing and Supply chains, Springer, ISBN 978-3-319-27521-5

[6] Fusko, M., Buckova, M., Gaso, M.,Krajcovic, M., Dulina, L.,Skokan, R.: Concept of Long-Term Sustainable Intralogistics in Plastic Recycling Factory, Sustainability, vol. 11, no. 23, 2019, DOl10.3390/su11236750

[7] Siemens Digital Industry Software - Proform Fact Sheet

[8] MARCHAL P., ORTEGA J., GARCÍA J.: Production Planning, Modeling and Control of Food Industry Processes, Spirnger, 2019, ISBN 978-3-03001373-8.

[9] Abel J. ARC Market Analysis - Manufacturing Execution Systems for the Discrete Induestries 2017 - 2022. 